Revista Ibero-Americana de Ciências Ambientais

Ibero-American Journal of Environmental Sciences

Edição Especial do Congresso de Gestão Ambiental do Baixo Amazonas

(CONGABA) Ago 2018 - v.9 - n.6

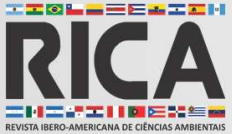

ISSN: 2179-6858

\title{
Rentabilidade econômica de propriedades rurais em Paragominas (PA) com o suporte de geoprocessamento
}

A dinâmica produtiva do setor agropecuário promove a criação de empregos/ocupações em suas várias atividades, tanto nos segmentos ligados à agricultura, quanto nos inerentes à pecuária. Paragominas, município localizado na mesorregião do nordeste do estado do Pará, destaca-se quanto ao seu crescimento no setor agropecuário, mantendo vigoroso crescimento econômico e melhora nos indicadores sociais, o que pode ser resultado de uma combinação de investimentos na intensificação do uso da terra. Portanto, o objetivo deste estudo é analisar a rentabilidade, levando em consideração a área do imóvel rural e o valor bruto de produção (VBP), oriundo das diferentes classes produtivas do setor agrícola no município. Para a realização deste trabalho, utilizou-se informações vetoriais e trabalhos de campo em 143 propriedades. Os principais tipos de atividade produtiva considerados foram os que obtiveram um valor de deste trabalho, utilizou-se informações vetoriais e trabalhos de campo em 143 propriedades. Os principais tipos de atividade produtiva considerados foram os que obtiveram um valor de
produção mais significativo que as demais. As propriedades rurais analisadas têm sua produção majoritária distribuída em oito classes, que são: criação de animais de pequeno, médio e grande porte; cultura permanente e temporária; horticultura e extração madeireira e não madeireira, que juntas somam um VBP de $R \$ 51.708 .600,00$. Dessas classes, a criação de animais de grande porte foi a que obteve maior predominância, ocupando $48 \%$ do total de propriedades, sendo a pecuária a atividade que mais se destacou nessa classe. A criação de animais de pequeno porte foi a que obteve a maior rentabilidade e uma das menores áreas. Outra classe que obteve alta rentabilidade foi a criação de animais de médio porte. Podemos notar que as duas classes de produção que necessitam das menores áreas foram as que obtiveram a maior rentabilidade, pois sua produção é adensada. Desse modo, observa-se a importância de estudos a respeito da eficiência e sustentabilidade das atividades rurais, devido a diversidade de atividades desenvolvidas, bem como, a rotatividade econômica advinda da produção rural. Esperase que cada propriedade cumpra sua função social, assim, contribuindo para a geração de renda local e servindo de base para estudos que visam o melhor conhecimento das ocupações na região Amazônica.

Palavras-chave: Paragominas; Imóvel rural; Classes produtivas; Valor bruto de produção; Rentabilidade.

\section{Economic profitability of rural properties in Paragominas (PA) with geoprocessing support}

The productive dynamics of the agricultural sector promotes the creation of jobs / occupations in its various activities, both in the segments related to agriculture and those inherent to The productive dynamics of the agricultural sector promotes the creation of jobs / occupations in its various activities, both in the segments related to agriculture and those inherent to improving social indicators, which may be the result of a combination of investments in intensifying land use. Therefore, the objective of this study is to analyze the profitability, taking into improving social indicators, which may be the result of a combination of investments in intensifying land use. Therefore, the objective of this study is to analyze the profitability, taking into
consideration the area of the rural property and the gross value of production (VBP), coming from the different productive classes of the agricultural sector in the municipality. For this work, we used vector information and field work in 143 properties. The main types of productive activity considered were those that obtained a more significant production value than the others. The rural properties analyzed have their majority production distributed in eight classes, which are: raising of small, medium and large animals; permanent and temporary culture; horticulture and logging and non-logging, which together add up to a VBP of $\mathrm{R} \$ 51,708,600$. Of these classes, the creation of large animals was the one that obtained the highest predominance, occupying $48 \%$ of the total properties, with livestock being the activity that stood out in this class. Small animal husbandry was the one with the highest profitability and one of the smallest areas. Another class that obtained high profitability was the breeding of medium sized animals. We can see that the two classes of production that need the smallest areas were the ones that obtained the highest profitability, because their production is denser. Thus, it is observed the importance of studies on the efficiency and sustainability of rural activities, due to the diversity of activities developed, as well as the economic turnover from rural production. Each property is expected to fulfill its social function, thus contributing to the generation of local income and serving as a basis for studies aimed at better knowledge of occupations in the Amazon region.

Keywords: Paragominas; Rural property; Productive classes; Gross value of production; Profitability

Topic: Desenvolvimento, Sustentabilidade e Meio Ambiente

Reviewed anonymously in the process of blind peer.

Marcos Vinicius Lima Chaves

Universidade do Estado do Pará, Brasil

http://lattes.cnpq.br/8871299629946462

marcosvlchaves@gmail.com

Yago Yguara Parente (iD

Universidade do Estado do Pará, Brasil

http://lattes.cnpq.br/9881335407140920

http://orcid.org/0000-0002-7932-1848

yagoparente96@gmail.com

Nicola Saverio Holanda Tancredi

Universidade do Estado do Pará, Brasil

http://lattes.cnpq.br/9699217049203328

eng.nsht@gmail.com

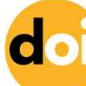

DOI: 10.6008/CBPC2179-6858.2018.006.0021
Received: $18 / 08 / 2018$

Approved: 25/08/2018

Florene Belato Tavares

Universidade do Estado do Pará, Brasil http://lattes.cnpq.br/2208627510426256

florenebelato@hotmail.com

Philipe Souza Simões

Universidade Federal Rural da Amazônia, Brasil

http://lattes.cnpq.br/2183187525357447

http://orcid.org/0000-0002-3909-8821

philipe.simoes@outlook.com

Referencing this:

CHAVES, M. V. L.; PARENTE, Y. Y.; TANCREDI, N. S. H.; TAVARES, F. B.; SIMÕES, P. S.. Rentabilidade econômica de propriedades rurais em Paragominas (PA) com o suporte de geoprocessamento. Revista Ibero-Americana de Ciências Ambientais, v.9, n.6, p.199-212, 2018. DOI: http://doi.org/10.6008/CBPC2179-6858.2018.006.0021 


\section{INTRODUÇÃO}

Segundo o Ministério da Agricultura, Pecuária e Abastecimento (2017), que levou em consideração os estudos do Departamento de Agricultura dos Estados Unidos, o Brasil é um dos países em que a produtividade agrícola mais cresce atualmente. De 2006 a 2010, o rendimento da agropecuária aumentou 4,28\% ao ano no Brasil. Segundo a Fundação Amazônia de Amparo a Estudos e Pesquisas do Pará - FAPESPA, a relevância da pecuária na matriz econômica paraense está expressa na sua participação de 54\% do PIB do setor primário ao passo que a área cultivada no estado do Pará, em 2013, atingiu 1.149.309ha, gerando uma produção de mais de 9,1 milhões de toneladas, com valor estimado em torno de $\mathrm{R} \$ 5,4 \mathrm{bi}$.

Assim, o crescimento agrícola pode se constituir em importante vetor para a redução da pobreza no Pará, já que o crescimento proveniente da agricultura é pelo menos duas vezes mais eficaz na redução da pobreza do que o crescimento do PIB gerado fora da agricultura. Por isso, a dinâmica produtiva do setor agropecuário promove a criação de empregos/ocupação em suas várias atividades, tanto nos segmentos ligados à agricultura quanto nos inerentes à pecuária e à pesca. Ademais, de acordo com dados disponibilizados pelo Instituto Brasileiro de Geografia e Estatística, em 2013, foram registrados no Pará 796.079 trabalhadores em ocupações ligadas ao setor agropecuário, desempenhando atividades eminentemente primárias.

Nessa perspectiva, em 2007 o município de Paragominas foi o maior produtor paraense de milho, o quarto maior de soja, o quinto de arroz e o terceiro maior produtor de madeira em tora oriunda de florestas plantadas (PINTO et al., 2009). Ainda de acordo com Pinto et al. (2009), ao contrário de outros municípios da Amazônia onde a dinâmica do 'boom-colapso' tem sido a regra, Paragominas conseguiu evitar o colapso econômico, mantendo vigoroso crescimento econômico e melhora nos indicadores sociais, o que pode ser resultado de uma combinação de investimentos na intensificação do uso da terra (pecuária, cultivo de grãos e reflorestamento) e melhoria na gestão pública, por exemplo.

A economia do município de Paragominas é baseada na pecuária de corte, em pastagens que surgiram a partir de queimadas e derrubadas da floresta nativa; na indústria extrativa madeireira, agricultura de subsistência e, também, em culturas de exportação como pimenta-do-reino, soja e milho (RODRIGUES et al. 2003).

Portanto, o objetivo deste estudo é justamente analisar as diferentes classes produtivas do setor agrícola no município de Paragominas (PA). Contudo, destaca-se que para analisar a rentabilidade da produção rural de um determinado município é necessário também levar em consideração o Valor Bruto de Produção (VBP): expressão monetária da soma de todos os bens e serviços produzidos em determinado território econômico, num dado período. Logo, pretende-se classificar as categorias, comparar a lucratividade entre atividades de mesma classe e equiparar rentabilidade entre classe distintas, considerando o universo de dados representativos de 143 propriedades rurais entrevistadas na área de estudo. 


\section{METODOLOGIA}

\section{Área De Estudo}

Paragominas, área de estudo deste trabalho, localiza-se na mesorregião do nordeste paraense. Possui uma área de aproximadamente $19.350 \mathrm{~km}^{2}$ e tem população estimada de 110 mil habitantes em 2017, segundo o Instituto Brasileiro de Geografia e Estatística (IBGE). A principal via de comunicação e transporte do município é a BR-010 (Belém-Brasília), ligando Paragominas à Belém e ao Centro-Sul do país.

Bastos et al. (2006) define que o clima da área de estudo é classificado como quente e úmido do tipo tropical chuvoso com expressivo período de estiagem, segundo a classificação de Köppen, com médias de temperatura e umidade relativa do ar de $26,3^{\circ} \mathrm{C}$ e $81 \%$, respectivamente. Além disso, localiza-se no Domínio Morfo-estrutural das Bacias e Coberturas Sedimentares Fanerozoicas, sendo a unidade geomorfológica o Planalto Dissecado do Gurupi - Grajaú, com altitude de aproximadamente 90m acima do nível médio dos mares não perturbados (IBGE, 2008).

A vegetação natural da região é caracterizada em floresta equatorial subperenifólia densa submontana, floresta equatorial subperenifólia densa das terras baixas e floresta equatorial perenifólia densa aluvial. Sobre a classificação dos solos predominantes na região, destacam-se os: Latossolos Amarelos; Argissolos Amarelos; Plitossolos; Gleissolos e Neossolos; estes foram mapeados e classificados tendo como base os critérios e características diferenciais para enquadramento no Sistema Brasileiro de Classificação de Solos da Empresa Brasileira de Pesquisa Agropecuária (RODRIGUES et al. 2003). A figura 01 espacializa a distribuição das 143 propriedades investigadas.

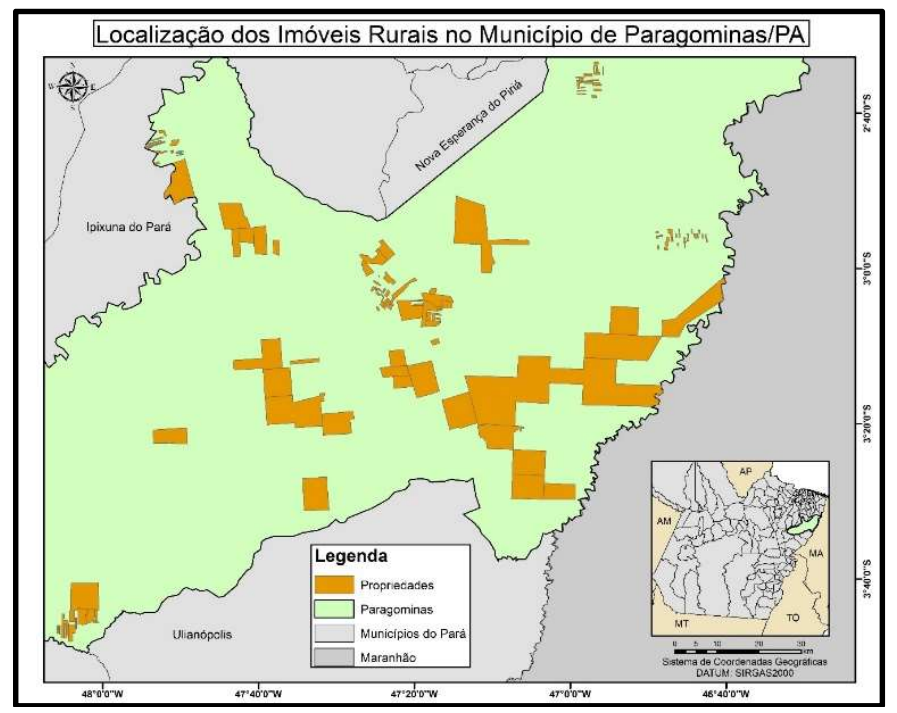

Figura 1: Localização dos Imóveis Rurais.

\section{Dados De Campo}

Os dados de campo foram obtidos através de Tancredi (2014) que foi um trabalho derivado do Projeto Amazônia Rede Sustentável (GARDNER, 2013). Tancredi (2014) buscava ter uma melhor compreensão sobre a realidade socioeconômica ambiental na Amazônia. Tal trabalho foi aplicado em 479 estabelecimentos rurais nos municípios de Paragominas e Santarém, qualificando os territórios e sistemas 
agrários. Foram aplicados questionários aos donos das propriedades, onde, através destes questionários, a espacialização geográfica de tais estabelecimentos consistiu no levantamento de insumos geoespaciais disponíveis e digitalização de cada propriedade considerando uma chave primária.

Foram plotadas as coordenadas geográficas das sedes e os transectos, que consistiam em seções no terreno que foram utilizadas como unidades amostrais do projeto e estavam inseridas no interior das propriedades rurais entrevistadas. Para a formulação da base vetorial das propriedades, foram utilizadas as informações retiradas dos questionários como: nome do proprietário; nome da propriedade; estrada/km; coordenada da sede em UTM; local da entrevista; uso da terra, tamanho da propriedade e o número de protocolo.

O questionário socioeconômico ambiental aplicado nas propriedades buscava obter informações como: informações do proprietário e da propriedade; arrendamentos; demografia; renda; financiamento; educação; espécies plantadas, interesse em mudanças na forma de produção; criação de animais; manejo florestal; mão-de-obra, entre outros. Essas informações foram agregadas em 4 grandes categorias: produção, custos de produção, força de trabalho e remuneração externa. Os dados da categoria 'produção' foram englobados em 9 grupos: culturas permanente e temporária, extrativismos madeireiro e não madeireiro, horticultura e pecuárias leiteira, pequena, média e de grandes animais.

Coletaram-se dados referentes à quantidade produzida, valor e renda bruta para o primeiro ano da produção, 2006 e 2009; tipos de unidades de produção e venda em seus variados formatos. Tal trabalho buscou testar se é possível explicar as diferenças territoriais, a partir da diversidade de estruturas, explicitadas pelas trajetórias tecnológicas, utilizando recursos das geotecnologias.

\section{Projeto Terraclass}

O Projeto TerraClass é composto por dados fornecidos pelo INPE (Instituto Nacional de Pesquisas Espaciais), que fornecem informações de uso e cobertura de terras desflorestadas da Amazônia Legal Brasileira, onde utiliza dados Landsat-5 e MODIS para o mapeamento (ALMEIDA et al., 2016). O projeto já mapeou cinco anos de uso e cobertura do solo (2004, 2008, 2010, 2012 e 2014), na qual, para esse trabalho, foram usados dados do ano de 2010, pois é o mesmo ano de realização do trabalho de campo, possibilitando uma avaliação mais precisa do uso e ocupação da área de estudo. Foram utilizadas as classes predominantes em cada propriedade.

\section{Etapas Metodológicas}

Para a realização deste trabalho, utilizou-se informações vetoriais e planilhas geradas através de pesquisas em campo fornecidas por Tancredi (2014) para categorizar as propriedades de acordo com a produção. Foram utilizadas informações de 143 propriedades que tinham como classes produtivas: pecuária (leiteiros, pequeno, médio e grande porte), extração madeireira e não madeireira, horticultura e agriculturas permanente e temporária. Dentro de cada classe produtiva, havia o tipo de atividade produtora executada na propriedade, ocorrendo subclassificações para cada classe. 
A cultura permanente apresentou 33 tipos de atividades produtivas, a cultura temporária 27 variedades, a extração madeireira 42 subclassificações, a extração não madeireira 17, a horticultura 29 tipos, a pecuária leiteira 3 subclassificações, pecuária de médios animais apresentou 3 variedades, pecuária de pequenos animais 11 tipos e a pecuária de grandes animais 7 contagens. Porém, os principais tipos de atividade produtiva considerados estão apresentados na tabela abaixo (tabela 1), pois foram as subclasses que obtiveram um valor de produção mais significativo que as demais e que serão utilizadas no presente trabalho.

Tabela 1: Principais tipos de atividades produtivas de cada classe.

\begin{tabular}{|l|l|l|l|l|l|l|l|}
\hline \multicolumn{2}{|c|}{ Criação de Animais } & Cultura Permanente & Cultura Temporária & Extração Madeireira & Extraçãonão Madeireira & Horticultura \\
\hline Grande Porte & Médio Porte & Pequeno Porte & Mamão & Arroz & Angelim & Açaí & Cheiro verde \\
\hline Bovino & Porco & Galinha & Pimenta do reino & Farinha & Carvão & Banana & Jambú \\
Búfalo & & & & Mandioca bruta & Espécie florestal & Caju & \\
Cavalo & & & & Mandioqueiro & Jarana & Laranja & \\
Mula & & & & Milho & Maçaranduba & Seringa & \\
\cline { 1 - 5 } & & & & Soja & Não sabe espécie florestal & & \\
\hline \hline
\end{tabular}

Para cumprir um dos objetivos do trabalho, foi calculada a rentabilidade da atividade predominante de cada propriedade. Esse cálculo foi feito através da divisão do valor bruto de produção do tipo de atividade produtiva preponderante $\left(\mathrm{VBP}_{\mathrm{AP}}\right)$, também chamada de rentabilidade parcial, naquele estabelecimento rural dividido pela área total da propriedade, ou seja, foram consideradas as atividades produtivas que apresentavam maior contribuição para o valor bruto de produção de toda a propriedade, e distribuiu-se o $\mathrm{VBP}_{\mathrm{AP}}$ daquela atividade para toda a área do imóvel, como se aquele tipo de atividade fosse exercido em toda a extensão da propriedade. $\mathrm{A}$ equação Rentabilidade $\mathrm{Parcial}=\mathrm{VBP}_{\mathrm{AP}} / \mathrm{A}$, sendo $\mathrm{VBP}_{\mathrm{AP}}=$ Valor $\mathrm{Bruto}$ de Produção da Atividade Predominante; e A = Área total da propriedade.

Para o cálculo da rentabilidade das classes de produção, foi utilizado o mesmo procedimento. Porém, como várias propriedades, que se enquadravam na mesma classe de produção, apresentaram diferentes valores brutos de produção e diferentes áreas, foram utilizadas as médias dos VBP e dos valores da área de todas as propriedades de mesma classe para o cálculo da rentabilidade das classes de produção.

Também foi calculada a rentabilidade da propriedade em geral, utilizando o valor bruto de produção de todas as atividades do imóvel $\left(\mathrm{VBP}_{\mathrm{t}}\right)$ dividido pela área total, como demonstrado na equação. $\mathrm{O}$ valor obtido serve como parâmetro para comparação com a rentabilidade parcial. A equação é: Rentabilidade Total= $\mathrm{VBP}_{\mathrm{t}} / \mathrm{A}$, sendo $\mathrm{VBP}_{\mathrm{t}}=$ Valor Bruto Total de Produção da Propriedade; e A=Área total da propriedade.

\section{RESULTADOS E DISCUSSÃO}

\section{Distribuição das Atividades Produtivas}

De acordo com os dados obtidos e entre as propriedades pesquisadas, a atividade produtiva que apresentou maior ocorrência foi a criação de animais de grande porte, a qual foi averiguada em 69 propriedades. Segundo Dias-Filho (2011), a pecuária, com destaque para a criação de bovinos, é uma atividade comumente utilizada para a ocupação de grandes áreas, já que se tratam de uma alternativa menos 
onerosa e mais eficiente para assegurar a posse de grandes extensões de terra, bem como, quando realizada de forma mais tradicional, necessita de poucos insumos e menos cuidados com a terra. A figura 02 apresenta as atividades predominantes por propriedade entrevistada.

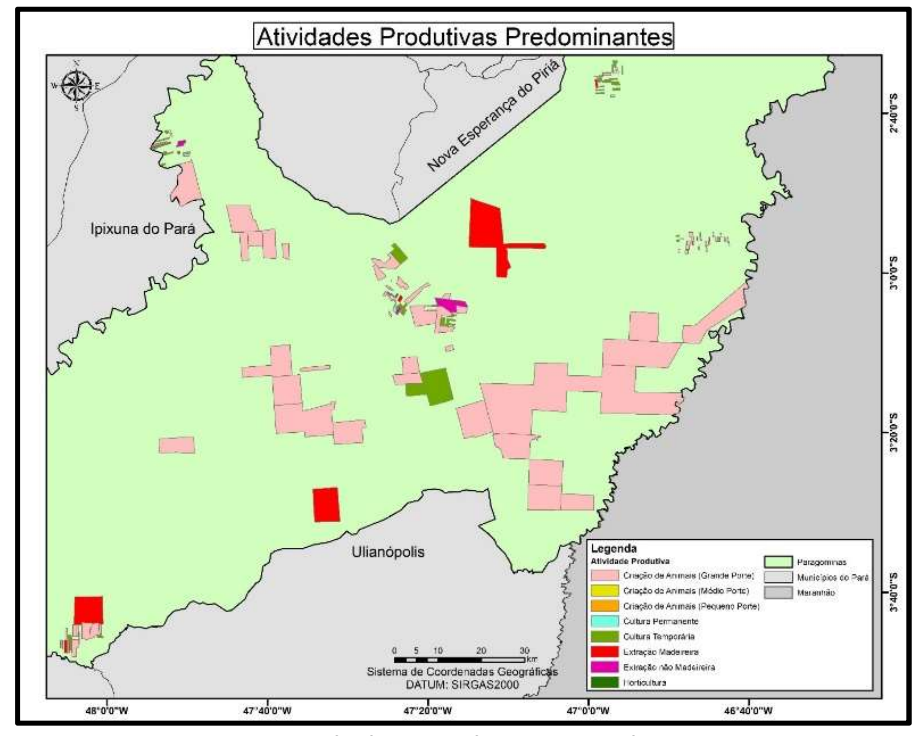

Figura 2: Atividades produtivas predominantes.

Ademais e no que diz respeito a produção animal, o modelo de desenvolvimento dessa atividade é dividido basicamente em duas fases: primária (crescimento horizontal), que se distingue por um fluxo migratório inicial intenso de produtores e rápida taxa de expansão da produção animal; e secundária (crescimento vertical) que é marcada por eventos de abandono ou de intensificação da atividade pecuária (DIAS-FILHO, 2010). Destaca-se que boa parte das propriedades que exercem as práticas de criação de animais de grande porte são de grande porte. A comparação pode ser realizada através da análise entre as figuras 2 e a 5 .

A criação de animais de grande porte é seguida pela agricultura temporária, predominante em 45 propriedades, a extração madeireira predomina em 13 imóveis, e a não madeireira em 8 imóveis. Segundo Costa (2012), as culturas temporárias podem ser definidas como culturas de ciclo curto e, segundo Oliveira (2008), são aquelas sujeitas ao plantio e replantio com um período de duração de até um ano.

Quanto ao setor extrativo madeireiro, Caneppele et al. (2013) salienta que, ainda hoje, o Brasil possui evidente relevância sobre diversas áreas, como na economia, no ambiente e no social. Além disso, o estado do Pará é uma importante fonte de geração de empregos, rendas e divisas. Ademais, nos últimos anos o Instituto de Desenvolvimento Florestal do Estado do Pará (IDEFLOR) implementou políticas de gestão para fomentar a extração, pela inciativa privada, de recursos florestais, tendo diversas áreas públicas concedidas para essa finalidade (SANTANA et al., 2012).

Em relação a extração não madeireira, também conhecida como Produtos Florestais Não Madeireiros (PFNMs), Machado (2008) expõe que este conceito se refere ao extrativismo sustentável ou neoextrativismo. Assim e, apesar de em termos macroeconômicos serem pouco significativos, os PFNMs são fundamentais para a sobrevivência de populações rurais tradicionais ou agroextrativistas, pois exige pouca renda monetária e tem a capacidade de atender o autoconsumo (PEDROZO, 2011). 
Por fim, ao se analisar a espacialização das atividades de extração madeireira e não madeireira, percebe-se que a madeireira ganha em área, ao passo que a não madeireira se sobrepõe em ocorrência nas propriedades. Segundo Mattei (2014), também conhecida como agricultura de subsistência, a PFNM é muitas vezes atrelada a agricultura familiar, sendo caracterizada por propriedades pequenas. Por fim, as demais atividades, criação de animais de médio e pequeno porte, cultura permanente e horticultura apresentaram sucinta ocorrência na área de estudo, como demonstrado na figura 3.

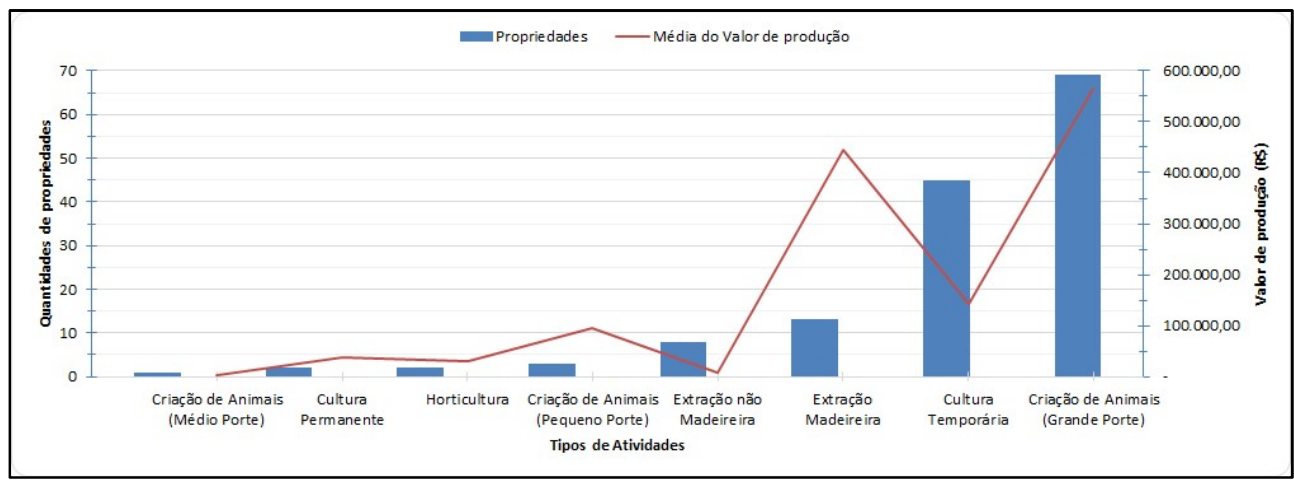

Figura 3: Atividades preponderantes por propriedade

A figura 3 reafirma a predominância da criação de animais de grande porte entre as 143 propriedades rurais do estudo e também demonstra a distribuição das outras classes, exibindo, conjuntamente, os valores médios de produção de cada atividade produtiva, onde nota-se a maior média de valor de produção na criação de animais de grande porte, influenciada pelo grande número de propriedades com essa atividade produtiva. Importante notar que a cultura temporária ocorre em mais propriedades do que a extração madeireira. Porém, a extração madeireira apresenta maior média do valor de produção, aproximadamente $\mathrm{R} \$ 445.000,00$ (quatrocentos e quarenta e cinco mil reais), em relação à cultura temporária, que registrou aproximadamente $\mathrm{R} \$ 142.000,00$ (cento e quarenta e dois mil reais).

Ao prosseguir com a análise dos dados, apresenta-se figura 4, que expõe a comparação do rendimento total e parcial, sendo este último representado pela atividade que obteve maior predominância, por propriedade. Para a criação de animais de grande porte, extração madeireira e cultura temporária, a maioria das propriedades apresentaram valores próximos de rendimento total e parcial, visto que a atividade preponderante representou parte significativa ou total do valor bruto das mesmas.

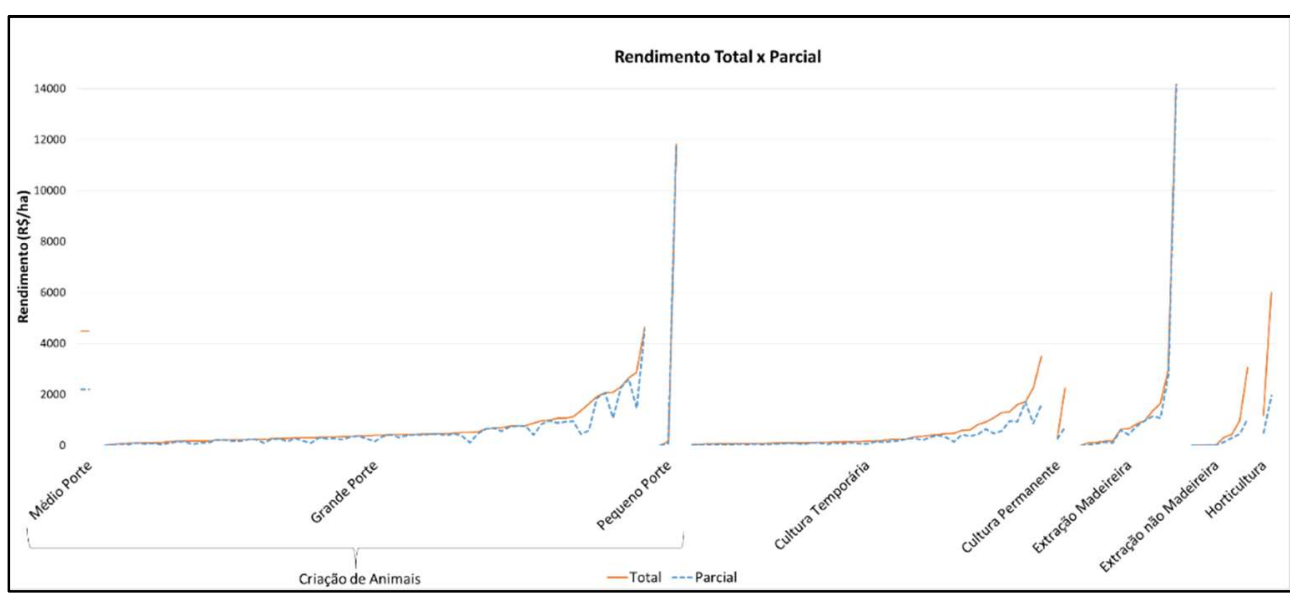

Figura 4: Rendimento total e parcial das propriedades analisadas. 
No que diz respeito à criação de animais de médio porte, a única propriedade pertencente a essa classe apresentou rendimento total bastante superior ao parcial, enquanto a de pequeno porte obteve valores próximos quanto ao rendimento. No entanto, a cultura permanente, extração não-madeireira e horticultura evidenciaram resultados do rendimento total superior ao parcial, indicando que a propriedade contém diversas atividades produtivas.

Analisando a figura 5, constatou-se a presença de 68 minifúndios (menor que 55ha) entre os 143 imóveis, enquanto que se identificou apenas 29 propriedades de grande porte (maior que 825ha), tendo um número menor até mesmo do que as propriedades de pequeno porte (entre 55 e 220ha), as quais apresentaram 35 propriedades. Imóveis de médio porte (superior a 220 até 825ha) representaram 11 propriedades entrevistadas.

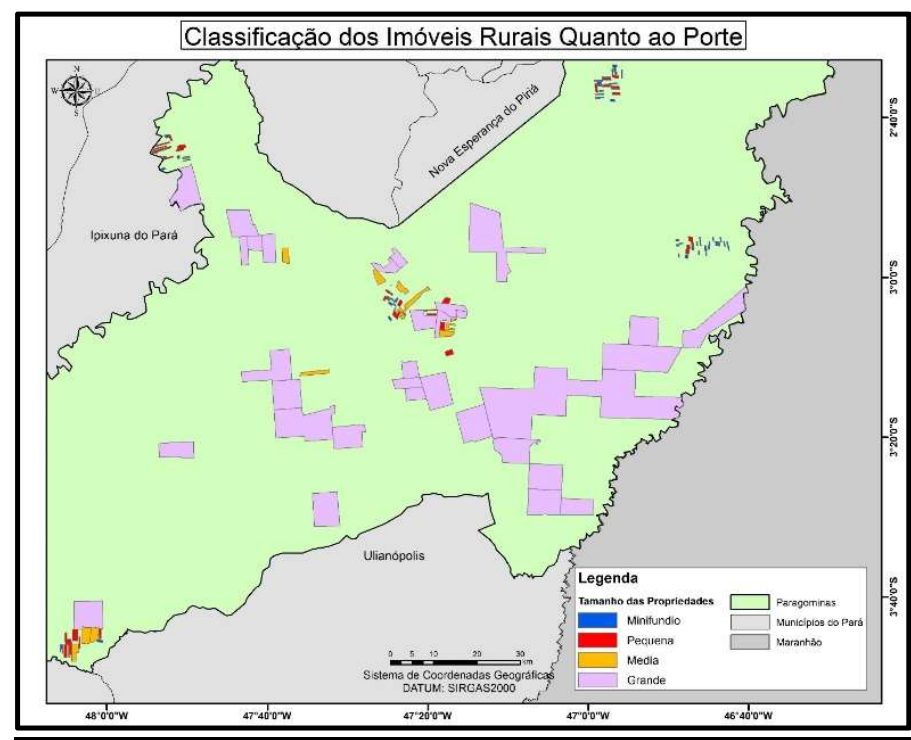

Figura 5: Classificação das propriedades rurais quanto ao porte.

Através de verificações estatísticas, foi possível averiguar que grande parte das grandes e médias propriedades apresentaram um maior valor bruto de produção (VBP) do que as pequenas propriedades e minifúndios, porém, ocorreram casos em que o VBP de propriedades de pequeno porte e minifúndios superaram o de grandes e médias propriedades. A figura 6 seguir bosqueja o discutido.

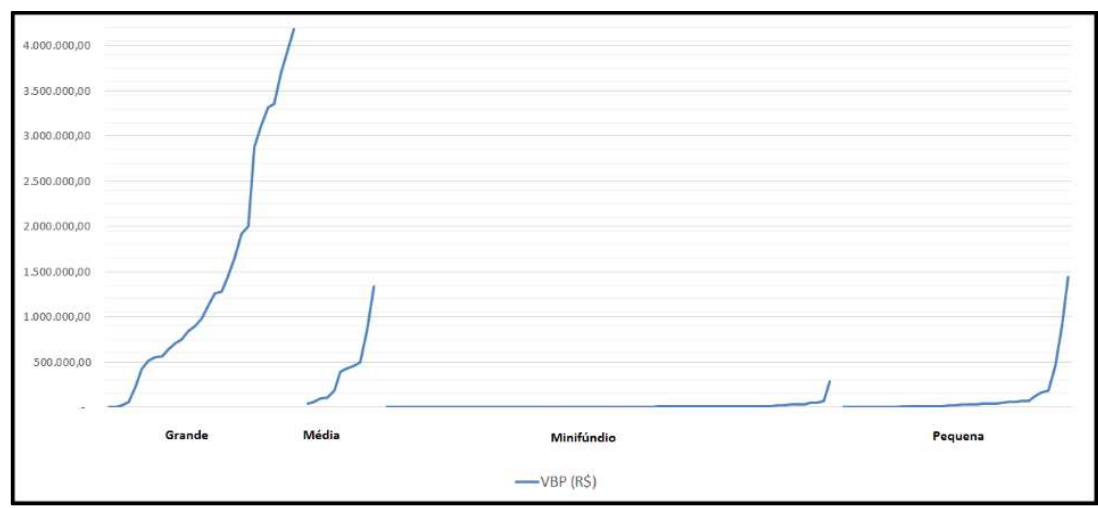

Figura 6: Valor Bruto de Produção de acordo com o tamanho da propriedade. 


\section{Comparação entre as classes produtivas}

As 143 propriedades rurais analisadas têm sua produção majoritária distribuída em oito classes, que são: Criação de animais de pequeno, médio e grande porte, cultura permanente e temporária, horticultura e extração madeireira e não madeireira, que juntas somam um VBP de $\mathrm{R} \$ 51.708 .600,00$ (cinquenta e um milhões, setecentos e oito mil, e seiscentos reais).

Dessas classes, a criação de animais de grande porte foi a que obteve maior predominância, ocupando $48 \%$ do total de propriedades, a pecuária foi a atividade que mais se destacou nessa classe. Outra categoria produtiva que apresentou grande predominância foi a cultura temporária, que foi majoritária em $31 \%$ das propriedades, enquanto que as demais categorias não ultrapassaram 10\%, estando distribuídas da seguinte maneira: extração madeireira com 9\%; extração não madeireira, 6\%; criação de animais de pequeno porte, 2\%; horticultura, cultura permanente e criação de animais de médio porte, todas ocupando 1\% das propriedades analisadas. A tabela 2 mostra uma síntese desses resultados.

Tabela 2: Valor de produção e quantidade de propriedades por classes produtivas.

\begin{tabular}{|c|c|c|c|c|}
\hline \multirow{2}{*}{ Classes produtivas } & \multicolumn{2}{|c|}{ Valor de produção (R\$) } & \multicolumn{2}{|c|}{ Propriedades } \\
\hline & Soma & Média & Quantidade & $\%$ \\
\hline Criação de animais (Grande Porte) & $39.049 .801,50$ & $565.939,15$ & 69 & $48 \%$ \\
\hline Cultura temporária & $6.385 .242,00$ & $141.894,27$ & 45 & $31 \%$ \\
\hline Extração madeireira & $5.784 .564,00$ & $444.966,46$ & 13 & $9 \%$ \\
\hline Extração não madeireira & $61.725,00$ & $7.715,63$ & 8 & $6 \%$ \\
\hline Criação de animais (Pequeno Porte) & $286.920,00$ & $95.640,00$ & 3 & $2 \%$ \\
\hline Horticultura & $60.960,00$ & $30.480,00$ & 2 & $1 \%$ \\
\hline Cultura permanente & $77.200,00$ & $38.600,00$ & 2 & $1 \%$ \\
\hline Criação de animais (Médio Porte) & $2.200,00$ & $2.200,00$ & 1 & $1 \%$ \\
\hline Total Geral & $51.708 .612,50$ & $361.598,69$ & 143 & $100 \%$ \\
\hline
\end{tabular}

Quanto ao valor total de produção de cada classe, a criação de animais de grande porte apresentou destaque, pois consegue arrecadar $\mathrm{R} \$ 39.049 .800,00$, os fatores que corroboram para esse elevado resultado são o alto valor médio da produção e a vasta ocupação das propriedades por esse tipo de atividade. A cultura temporária e a extração madeireira obtiveram valores aproximados, com respectivamente: $\mathrm{R} \$ 6.385 .200,00$ e $\mathrm{R} \$ 5.784 .500,00$, apesar de a cultura temporária apresentar maior predominância nas propriedades, o valor médio da extração madeireira é superior. Assim como nestas classes, a soma dos valores da extração não madeireira e horticultura foram próximos, porém também contaram com a quantidade de propriedades e valor médio bastante diferentes.

Quanto ao rendimento, levando em consideração o valor de produção médio e a média das áreas das propriedades de mesma classe produtiva, a criação de animais de pequeno porte foi a que obteve a maior rentabilidade e uma das menores áreas, isso porque a granja foi a atividade predominante, atividade que requer pequenas quantidades territoriais. Outra classe que obteve alto resultado de rentabilidade foi a criação de animais de médio porte, que apenas uma propriedade teve o seu predomínio e obteve uma pequena área produtiva. Podemos notar que as duas classes de produção que necessitam das menores áreas foram as que obtiveram a maior rentabilidade, pois sua produção é adensada. A tabela 3 mostra uma síntese desses resultados. 
Tabela 3: Rendimento das classes produtivas.

\begin{tabular}{|c|c|c|c|}
\hline \multirow{2}{*}{ Classes produtivas } & \multicolumn{2}{|c|}{ Área das propriedades (ha) } & \multirow{2}{*}{ Rendimento (R\$/ha) } \\
\hline & Soma & Média & \\
\hline Criação de Animais (Grande Porte) & $130.324,17$ & $1.888,76$ & 534,33 \\
\hline Cultura Temporária & $9.235,17$ & 205,23 & 287,13 \\
\hline Extração Madeireira & $19.827,88$ & $1.525,22$ & $1.706,47$ \\
\hline Extração não madeireira & $1.796,94$ & 224,62 & 243,52 \\
\hline Criação de Animais (Pequeno Porte) & 74,60 & 24,87 & $3.954,31$ \\
\hline Horticultura & 50,16 & 25,08 & $1.234,08$ \\
\hline Cultura Permanente & 138,67 & 69,34 & 494,02 \\
\hline Criação de Animais (Médio Porte) & 1,00 & 1,00 & $2.200,00$ \\
\hline Total Geral & $161.448,60$ & $1.129,01$ & 639,42 \\
\hline
\end{tabular}

\section{Comparação entre os tipos de produção de mesma classe}

Dentro das oito classes produtivas analisadas, foram listadas 27 atividades que apresentaram predominância nas propriedades rurais. Dentre todas, a pecuária bovina foi a atividade que mais ocorreu, com 66 propriedades, seguida do plantio de mandioca, com 36 propriedades, a qual apresentou uma divisão entre os produtores que comercializam a mandioca sem realizar nenhum processamento (mandioca bruta) e aqueles que fazem seu beneficiamento, transformando-a em farinha. As demais atividades não ultrapassaram um predomínio de 8 propriedades, ficando a maioria destas distribuídas, cada uma, em apenas um imóvel rural.

Quanto à criação de grandes animais, a atividade bovina ocorreu em um maior número, porém foi a criação de búfalos que obteve o maior rendimento. Segundo Marques (1998), a criação bufalina pode apresentar maior produção econômica do que a criação bovina, visto que o tempo de maturação do búfalo até o abate é menor, o rendimento industrial do leite de búfalo é $40 \%$ superior ao do bovino e também é mais nutritivo e ainda essa espécie possui organismos que permitem a digestão de alimentos grosseiros, que elevam a capacidade de produção de carne. As atividades de criação de cavalos e mulas apresentaram baixo rendimento quando comparadas com o restante.

A criação de animais de médio e pequeno porte apresentaram apenas duas atividades predominantes (criação de galinhas e porcos, respectivamente). Acerca da produção suína, tem-se que esta foi a que apresentou o terceiro maior rendimento de todas atividades, enquanto a criação de galinhas foi a que obteve o maior rendimento, chegando a quase $\mathrm{R} \$ 4$ mil por hectare. De acordo com Oviedo-Rondón (2008), a produção de frangos é altamente eficiente, pois necessita de um curto espaço de tempo para o abate, utilizam pouco espaço, pouca água e energia, além de que é possível utilizar o animal inteiro após o abate.

Ademais, as classes de agricultura (permanente, temporária e horticultura) obtiveram resultados semelhantes entre si, onde seu rendimento variou de 1.964,00 a 47,00R\$/ha. Quanto as atividades produtivas permanentes, o mamão apresentou o maior rendimento; já o jambu foi mais rentável na horticultura. Na classe de cultura temporária a soja foi a mais rentável, porém o milho foi o que apresentou maior valor médio de produção e área e, levando em consideração o número de propriedades, a mandioca (bruta e farinha) foi a mais presente entre as classes de agricultura. 
Em sequência e, ao analisar os resultados obtidos e comparar a extração madeireira e a não madeireira, a que apresentou maior rentabilidade foi a madeireira. Nessa perspectiva e, entre a classe de extração madeireira tem-se a maior ocorrência e rendimento para a produção de carvão vegetal, sendo identificada em 8 propriedades como atividade predominante. No mais, os outros imóveis rurais dividiramse em uma atividade por imóvel e seus respectivos rendimentos ficaram bem inferiores ao do carvão vegetal. Por sua vez, quanto a extração não madeireira o plantio de banana apresentou-se como o mais rentável. Contudo, o cultivo de açaí foi o que mais ocorreu, apesar de ter configurado a menor rentabilidade. A tabela 04 mostra uma síntese desses resultados.

Tabela 4: Rentabilidade das atividades produtivas.

\begin{tabular}{|c|c|c|c|c|c|}
\hline Classes produtivas & Atividade & $\begin{array}{l}\text { Quantidade de } \\
\text { propriedades }\end{array}$ & $\begin{array}{l}\text { Média do valor de } \\
\text { produção (R\$) }\end{array}$ & $\begin{array}{l}\text { Média da } \\
\text { área (ha) }\end{array}$ & $\begin{array}{c}\text { Média da } \\
\text { rentabilidade } \\
\text { (R\$/ha) }\end{array}$ \\
\hline \multirow{5}{*}{$\begin{array}{l}\text { Criação de Animais } \\
\text { (Grande Porte) }\end{array}$} & Búfalo & 1 & $850.000,00$ & 582,32 & $1.459,68$ \\
\hline & Bovino & 66 & $578.746,99$ & $1.965,01$ & 535,03 \\
\hline & Cavalo & 1 & $1.500,00$ & 25,73 & 58,29 \\
\hline & Mula & 1 & $1.000,00$ & 25,65 & 38,99 \\
\hline & TOTAL & 69 & $565.939,15$ & $1.888,76$ & 534,33 \\
\hline \multirow{2}{*}{$\begin{array}{l}\text { Criação de Animais } \\
\text { (Médio Porte) }\end{array}$} & Porco & 1 & $2.200,00$ & 1,00 & $2.195,45$ \\
\hline & TOTAL & 1 & $2.200,00$ & 1,00 & $2.195,45$ \\
\hline \multirow[t]{2}{*}{$\begin{array}{c}\text { Criação de Animais } \\
\text { (Pequeno Porte) }\end{array}$} & Galinha & 3 & $95.640,00$ & 24,87 & $3.954,31$ \\
\hline & TOTAL & 3 & $95.640,00$ & 24,87 & $3.954,31$ \\
\hline \multirow{3}{*}{$\begin{array}{c}\text { Cultura } \\
\text { Permanente }\end{array}$} & Mamão & 1 & $64.000,00$ & 87,91 & 727,98 \\
\hline & \begin{tabular}{|l|} 
Pimenta do reino \\
\end{tabular} & 1 & $13.200,00$ & 50,76 & 260,07 \\
\hline & TOTAL & 2 & $38.600,00$ & 69,34 & 494,02 \\
\hline \multirow{7}{*}{ Cultura Temporária } & Soja & 2 & $363.260,00$ & 608,73 & 920,52 \\
\hline & Arroz & 1 & $14.400,00$ & 16,52 & 871,90 \\
\hline & \begin{tabular}{|l|} 
Milho \\
\end{tabular} & 5 & $1.079 .151,60$ & $1.235,58$ & 832,03 \\
\hline & Farinha & 24 & $5.862,50$ & 41,68 & 175,49 \\
\hline & Mandioca bruta & 12 & $8.791,67$ & 64,41 & 149,07 \\
\hline & Mandioqueira & 1 & $2.364,00$ & 50,06 & 47,22 \\
\hline & TOTAL & 45 & $141.894,27$ & 205,23 & 287,13 \\
\hline \multirow{7}{*}{$\begin{array}{l}\text { Extração } \\
\text { Madeireira }\end{array}$} & Carvão & 8 & $217.602,00$ & $1.370,05$ & $2.614,60$ \\
\hline & Espécie florestal não informada & 1 & $3.960 .000,00$ & $4.131,75$ & 958,43 \\
\hline & Maçaranduba & 1 & $14.184,00$ & 109,72 & 129,28 \\
\hline & Não sabe espécie florestal & 1 & $2.364,00$ & 25,05 & 94,37 \\
\hline & Jarana & 1 & $7.200,00$ & 100,08 & 71,94 \\
\hline & Angelim & 1 & $60.000,00$ & $4.500,83$ & 13,33 \\
\hline & TOTAL & 13 & $444.966,46$ & $1.525,22$ & $1.706,47$ \\
\hline \multirow{6}{*}{$\begin{array}{c}\text { Extração não } \\
\text { madeireira }\end{array}$} & Banana & 1 & $3.000,00$ & 2,85 & $1.051,46$ \\
\hline & Laranja & 1 & $45.000,00$ & 99,45 & 452,51 \\
\hline & Seringa & 2 & $5.412,50$ & 25,51 & 210,81 \\
\hline & Caju & 1 & 200,00 & 25,24 & 7,92 \\
\hline & Açaí & 3 & 900,00 & 539,46 & 4,88 \\
\hline & TOTAL & 8 & $7.715,63$ & 224,62 & 243,52 \\
\hline \multirow{3}{*}{ Horticultura } & Jambu & 1 & $48.000,00$ & 24,44 & $1.964,38$ \\
\hline & \begin{tabular}{|l|} 
Cheiro verde \\
\end{tabular} & 1 & $12.960,00$ & 25,73 & 503,78 \\
\hline & TOTAL & 2 & $30.480,00$ & 25,08 & $1.234,08$ \\
\hline
\end{tabular}

\section{Comparação da acurácia do TerraClass}

Os 143 imóveis observados se enquadraram em 9 categorias rotuladas pelo TerraClass, sendo elas: Área Urbana, Desflorestamento, Mosaico de Ocupações, Não Floresta, Regeneração com Pasto, Agricultura anual, Floreta, Vegetação Secundária e Pasto. Deve-se destacar a classe Pasto que ocorreu em 62 propriedades da área de estudo. Isso ocorreu, também, devido à grande atividade de pecuária que ocorre na 
região. De acordo com Townsend et al. (2012), as extensas áreas de pastagens são predominantes na região amazônica e com a intensificação deste processo, vastas áreas de florestas foram substituídas por pastagens, despertando uma preocupação com relação aos impactos econômicos, sociais e ambientais.

Outro ponto em destaque é que mesmo apresentando somente 21 propriedades com classificação de Floresta, segundo o TerraClass, essa foi a categoria que apresentou maior área, 52.707,99ha. A figura 7 ilustra um compêndio dos resultados. É importante frisar que as classificações de Área Urbana, Desflorestamento, Mosaico de Ocupações e Não Floresta foram registradas em apenas 1 propriedade, com área menor que 40 ha. Relacionando-se a categoria de produção predominante de cada propriedade com a classe de uso e ocupação do solo segundo o TerraClass, obteve-se a tabela 5.

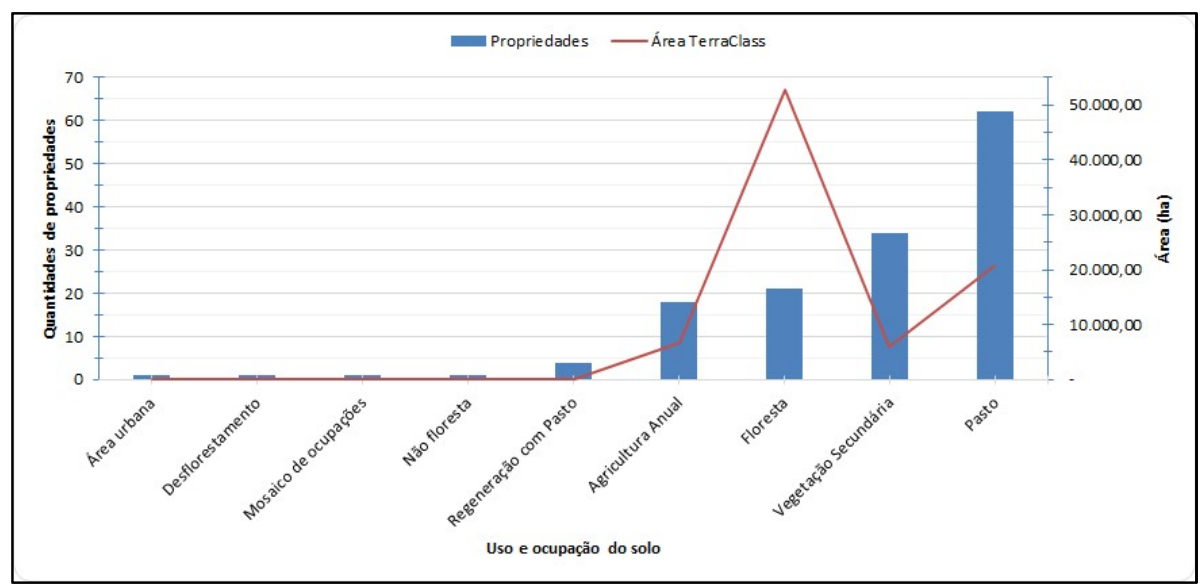

Figura 7: Classes de uso e ocupação do solo: TerraClass.

Tabela 5: Relação categoria de produção e uso e ocupação do solo: TerraClass.

\begin{tabular}{|c|c|c|}
\hline Categoria de produção & Classes de uso e ocupação - Terraclass & Quantidade de propriedades \\
\hline \multirow{5}{*}{ Criação de Animais (Grande Porte) } & Agricultura Anual & : \\
\hline & Área urbana & 1 \\
\hline & Floresta & 12 \\
\hline & Pasto & 34 \\
\hline & Vegetação Secundária & 16 \\
\hline Criação de Animais (Médio Porte) & Agricultura Anual & 1 \\
\hline \multirow{2}{*}{ Criação de Animais (Pequeno Porte) } & Agricultura Anual & 2 \\
\hline & Vegetação Secundária & 1 \\
\hline \multirow{2}{*}{ Cultura Permanente } & Agricultura Anual & 1 \\
\hline & Pasto & 1 \\
\hline \multirow{7}{*}{ Cultura Temporária } & Agricultura Anual & 6 \\
\hline & Desflorestamento & 1 \\
\hline & Floresta & 5 \\
\hline & Não floresta & 1 \\
\hline & Pasto & 18 \\
\hline & Regeneração com Pasto & 2 \\
\hline & Vegetação Secundária & 12 \\
\hline \multirow{5}{*}{ Extração Madeireira } & Floresta & 4 \\
\hline & Mosaico de ocupações & 1 \\
\hline & Pasto & 4 \\
\hline & Regeneração com Pasto & 2 \\
\hline & Vegetação Secundária & 2 \\
\hline \multirow{3}{*}{ Extração não madeireira } & Agricultura Anual & 2 \\
\hline & Pasto & 4 \\
\hline & Vegetação Secundária & 2 \\
\hline \multirow{2}{*}{ Horticultura } & Pasto & 1 \\
\hline & Vegetação Secundária & 1 \\
\hline
\end{tabular}


Analisando a tabela 5, pôde-se verificar certas inconsistências em relação aos dados fornecidos pelo TerraClass, por exemplo, na categoria de criação de animais de grande porte há a classificação de uma propriedade como área urbana, onde falta certa coerência nesse dado, já que Andrade et al. (2015) classifica área urbana como "Manchas urbanas decorrentes da concentração populacional". Considerando a criação de animais como a principal atividade da propriedade, não teria como se encaixar a classificação de área urbana no local. Outro ponto que deve ser destacado é a classificação de três propriedades como agricultura anual sendo que a principal atividade produtiva das três é a criação de animais. Porém, de maneira geral, os dados TerraClass apresentam certo grau de compatibilidade com os dados obtidos in loco, validando os dados de uso e ocupação do solo adquiridos por sensoriamento remoto.

\section{CONCLUSÕES}

Estudos referentes à principal fonte de renda de uma determinada região são de extrema valia em diversos contextos, visto que, são instrumento de desenvolvimento e gestão, podendo atuar na correção de deficiências econômicas, sociais e ambientais, bem como na realização de um prognóstico preciso da produção rural.

A obtenção dos dados in loco por Tancredi (2014) foram de suma importância para a acurácia das análises, juntamente com a diversidade dos tipos de dados, que foram cruciais para a definição das atividades rurais de maior expressividade econômica no município de Paragominas, definindo de forma detalhada as classes e subclasses de produção.

A pesquisa comprovou que a pecuária de corte é a atividade rural predominante nos 143 imóveis rurais analisados e, economicamente importante em Paragominas e no contexto nacional como atividade produtiva. A criação de animais de grande porte, de forma geral, destaca-se pelo valor de produção mais elevado dentre todas as classes estudadas, mostrando-se como uma atividade consolidada e extremamente rentável nesta dada região.

Apesar da menor percentagem de propriedades rurais que atuam na extração madeireira em relação aos imóveis onde a cultura temporária é predominante, a pesquisa possibilitou constatar o maior valor médio de produção e rentabilidade da extração madeireira, sendo também esta atividade mais rentável em relação à criação de animais de grande porte, visto que a área demandada para a criação é superior. $O$ estudo também proporcionou a comparação entre as atividades produtivas de mesma classe, definindo assim as atividades mais rentáveis dentro dela, de forma a gerar um banco de dados denso a respeito da interação entre área da atividade rural e valor de produção.

Desse modo, observa-se a importância de estudos e análises a respeito das atividades rurais desenvolvidas no município de Paragominas, devido a diversidade de atividades desenvolvidas, bem como, a rotatividade econômica advinda da produção rural, seja ela desenvolvida em propriedades de pequena, média ou grande área. Espera-se que cada propriedade cumpra sua função social, assim, contribuindo para a geração de renda local e servindo de base para estudos como este, que visam o melhor conhecimento e desenvolvimento das ocupações na região Amazônica. 


\section{REFERÊNCIAS}

ALMEIDA, C. A.; COUTINHO, A. C.; ESQUERDO, J. C. D. M.; ADAMI, M.; VENTURIERI, A.; DINIZ, C. G.; DESSAY, N.; DURIEUX, L.; GOMES, A. R.. High spatial resolution land use and land cover mapping of the Brazilian Legal Amazon in 2008 using Landsat-5/TM and MODIS data. Acta Amazônica, Manaus, v.46, n.3, p.291-302, 2016.

ANDRADE, A. S.; MIRANDA, M. V. C.; BRANDÃO, V. V. P.; BRAGA, T. G. M.; PEREIRA, B. W. F.; MARQUES, G. T.. Avaliação do uso e cobertura do solo no município de Parauapebas (PA) utilizando dados do projeto terraclass. In: CONGRESSO NACIONAL DE MEIO AMBIENTE, 12. Anais. Poços de Caldas: 2015.

BASTOS, T. X.; SILVA, G. F. G.; PACHECO, N. A.; FIGUEIREDO, R. O. Informações Agroclimáticas do município de Paragominas para o planejamento agrícola In: CONGRESSO BRASILEIRO DE METEOROLOGIA. Anais. Florianópolis: SBMET, 2006.

BRASIL. Brasil lidera produtividade agropecuária mundial. Brasília: MAPA, 2017.

CANEPPELE, F. L.; SERAPHIM, O. J.. Análise da eficiência energética em indústrias madeireiras através da lógica fuzzy. Revista Energia na Agricultura, Botucatu, v.28, n.2, p.95102, 2013.

COSTA, F. A.. Economia camponesa nas fronteiras do capitalismo: teoria e prática nos EUA e na Amazônia Brasileira. Belém: NAEA, 2012.

DIAS-FILHO, M. B.. Os desafios da produção animal em pastagens na fronteira agrícola brasileira. Revista Brasileira de Zootecnia, Belém, v.40, p.243-252, 2011.

DIAS-FILHO, M. B.. Produção de bovinos a pasto na fronteira agrícola. In: RODRIGUES, K. F.; FERREIRA, W. M.; MACEDO JUNIOR, G. L.. ZOOTEC 2010. CONGRESSO BRASILEIRO DE ZOOTECNIA, 20. Anais. Palmas: UFT, 2010.

FAPESPA. Boletim agropecuário do estado do Pará 2015 Belém: Governo do Estado do Pará, 2015. http://www.periodicos.unir.br/index.php/rara/article/view/2 $\underline{01 / 234}$

GARDNER, T. A.; FERREIRA, J.; BARLOW, J.; LEES, A. C.; PARRY L.; VIEIRA, I. C. G.; BERENGUER, E.; ABRAMOVAY, R.; ALEIXO, A.; ANDRETTI, C.; ARAGAO, L. E. O. C.; ARAUJO, I.; AVILA, W. S.; BARDGETT, R. D.; BATISTELLA, M.; BEGOTTI, R. A.; BELDINI, T.; BLAS, D. E.; BRAGA, R. F.; BRAGA, D. D. L.; BRITO, J. G.; CAMARGO, P. B.; SANTOS, F. C.; OLIVEIRA, V. C.; CORDEIRO, A. C. N.. A social and ecological assessment of tropical land uses at multiple scales: the Sustainable Amazon Network. Philosophical Transactions of the Royal Society B: Biological Sciences, v.368, 2013.
IBGE. Instituto Brasileiro de Geografia e Estatística. Mapa geomorfológico do Estado do Pará. Brasília: IBGE, 2008.

MACHADO, F. S.. Manejo De Produtos Florestais Não Madeireiros: um manual com sugestões para o manejo participativo em comunidades da Amazônia. Rio Branco: PESACRE, 2008.

MARQUES, J. R. F.. Criação de Búfalos. Brasília: EMBRAPA 1998.

MATTEI, L.. O papel e a importância da agricultura familiar no desenvolvimento rural brasileiro contemporâneo. Revista Economia do Nordeste, Fortaleza, v.45, p.71-79, 2014.

OLIVEIRA, N. C.. Contabilidade do agronegócio. Curitiba: Juruá, 2008.

OVIEDO-RONDÓN, E. O.. Tecnologias para mitigar o impacto ambiental da produção de frangos de corte. Revista Brasileira de Zootecnia, v.37, p.239-252, 2008.

PEDROZO, E. Á.; SILVA, T. N.; SATO, S. A. S.; OLIVEIRA, N. D. A.. Produtos Florestais Não Madeiráveis (PFNMS): as Filières do Açaí e da Castanha da Amazônia. Revista de Administração e Negócios da Amazônia, Rondônia, v.3, n.2, 2011.

PINTO, A.; AMARAL, P.; SOUZA JUNIOR., C.; VERÍSSIMO, A.; SALOMÃO, R.; GOMES, G.; BALIEIRO, C.. Diagnóstico Socioeconômico e Florestal do Município de Paragominas: Relatório Técnico. Belém: IHMAA, 2009.

RODRIGUES, T. E.; SILVA, R. C.; SILVA, J. M. L.; JÚNIOR, R. C. O.; GAMA, J. R. N. F.; VALENTE, M. A.. Caracterização e classificação dos solos do município de Paragominas, estado do Pará. Belém: Embrapa, 2003.

SANTANA, A. C.; SANTOS, M. A. S. SANTANA, Á. L.; YARED, J. A. G.. O valor econômico da extração manejada de madeira no Baixo Amazonas, Estado do Pará. Revista Árvore, Viçosa, v.36, n.3, p.527-536, 2012.

TANCREDI, N. S. H.. Trajetórias tecnológicas e sistemas agrários: qualificação territorial utilizando geoprocessamento em Paragominas e Santarém/PA. Tese (Doutorado em Desenvolvimento Sustentável do Trópico Úmido) - Universidade Federal do Pará, Belém, 2014.

TOWNSEND, C. R.; COSTA, N. L.; PEREIRA, R. G. A.. Pastagens nativas na Amazônia brasileira. Porto Velho: Embrapa Rondônia, 2012.

A CBPC - Companhia Brasileira de Produção Científica (CNPJ: 11.221.422/0001-03) detém os direitos materiais desta publicação. Os direitos referem-se à publicação do trabalho em qualquer parte do mundo, incluindo os direitos às renovações, expansões e disseminações da contribuição, bem como outros direitos subsidiários. Todos os trabalhos publicados eletronicamente poderão posteriormente ser publicados em coletâneas impressas sob coordenação da Sustenere Publishing, da Companhia Brasileira de Produção Científica e seus parceiros autorizados. Os (as) autores (as) preservam os direitos autorais, mas não têm permissão para a publicação da contribuição em outro meio, impresso ou digital, em português ou em tradução. 